\title{
Ruptured Posterior Fossa Teratoma Mimicking Intracranial Haemorrhage: A Case Report
}

\author{
Maia Osborne-Grinter, MBChB ${ }^{1^{*}}$, Julie Woodfield, PhD ${ }^{1,2}$, Ana M Casado Lopez, LMS ${ }^{2}$, Anna Solth, FCSEd \\ $(S N)^{3}$ and Mark A Hughes, PhD ${ }^{1,2}$
}

${ }^{1}$ Centre for Clinical Brain Sciences, University of Edinburgh, Edinburgh, UK

${ }^{2}$ Department of Clinical Neurosciences, NHS Lothian, Edinburgh, UK

${ }^{3}$ Ninewells Hospital and Medical School, Dundee, UK

*Corresponding author: Maia Osborne-Grinter, Centre for Clinical Brain Sciences, University of Edinburgh, Edinburgh, UK

\begin{abstract}
Background and importance: Posterior fossa mature teratomas are rare congenital lesions that contain differentiated tissue from all three germ cell layers. The imaging characteristics can be highly variable, reflecting the variety of potential tissue types.

Clinical presentation: A 22-year-old presented with headache, papilloedema, and diplopia. CT head showed a hyperdense lesion in the posterior fossa, initially suspicious of haemorrhage, with acute hydrocephalus. Digital subtraction angiogram was normal. MRI was suggestive of a melanin containing lesion. She underwent posterior fossa craniotomy and complete resection of the lesion. Intraoperatively, hair and calcification were found, suggestive of a dermoid or teratoma. Histological analysis confirmed a ruptured mature teratoma.
\end{abstract}

Conclusion: Due to its heterogenous imaging characteristics, and therefore inherent potential to mimic, teratoma should be considered in the differential diagnosis of a posterior fossa lesion with atypical imaging characteristics.

\section{Keywords}

Teratoma, Germ cell tumour, Posterior fossa, MRI

\section{Introduction}

Intracranial teratomas are rare congenital tumours. They are most frequently seen in children or young adults and are usually located in midline sellar or pineal regions [1-4]. Teratomas are particularly rare in adults, and few case reports of adult posterior fossa teratomas exist [5-7]. Complete resection of mature teratomas is generally reported to be curative $[4,5,8,9]$.

As teratomas contain differentiated tissue from all three germ cell layers (endoderm, ectoderm, mesoderm) they can have hugely variable characteristics on MRI and $\mathrm{CT}$, leading to diagnostic uncertainty. This is informed by differing quantities of fat, calcification, cysts, or keratinocytes $[1,10]$.

\section{Case Description}

A 22-year-old woman presented to her optician with a 2-month history of headache and a 10-day history of horizontal diplopia. She had no additional past medical history and was taking no regular medications. Her GCS was 15. Ophthalmological examination revealed bilateral VIth nerve palsies and papilloedema, but no other focal neurological deficits.

CT brain (Figure 1) illustrated a well-defined hyperdense lesion in the posterior fossa within which was foci of calcification, and secondary acute obstructive hydrocephalus. Spontaneous haemorrhage secondary to a vascular lesion was suspected due to the hyperdensity of the lesion and the presence of calcification. She underwent urgent external ventricular drainage (EVD), leading to resolution of her $\mathrm{VI}^{\text {th }}$ nerve palsies and headache.

Digital subtraction angiography (DSA) did not reveal any vascular abnormality nor tumour blush. MRI (Figure 2) showed a midline posterior fossa mass without

Citation: Grinter MO, Woodfield J, Lopez AMC, Solth A, Hughes MA (2022) Ruptured Posterior Fossa Teratoma Mimicking Intracranial Haemorrhage: A Case Report. Neurosurg Cases Rev 5:098. doi. org/10.23937/2643-4474/1710098

Accepted: February 10, 2022; Published: February 12, 2022

Copyright: (c) 2022 Grinter MO, et al. This is an open-access article distributed under the terms of the Creative Commons Attribution License, which permits unrestricted use, distribution, and reproduction in any medium, provided the original author and source are credited. 


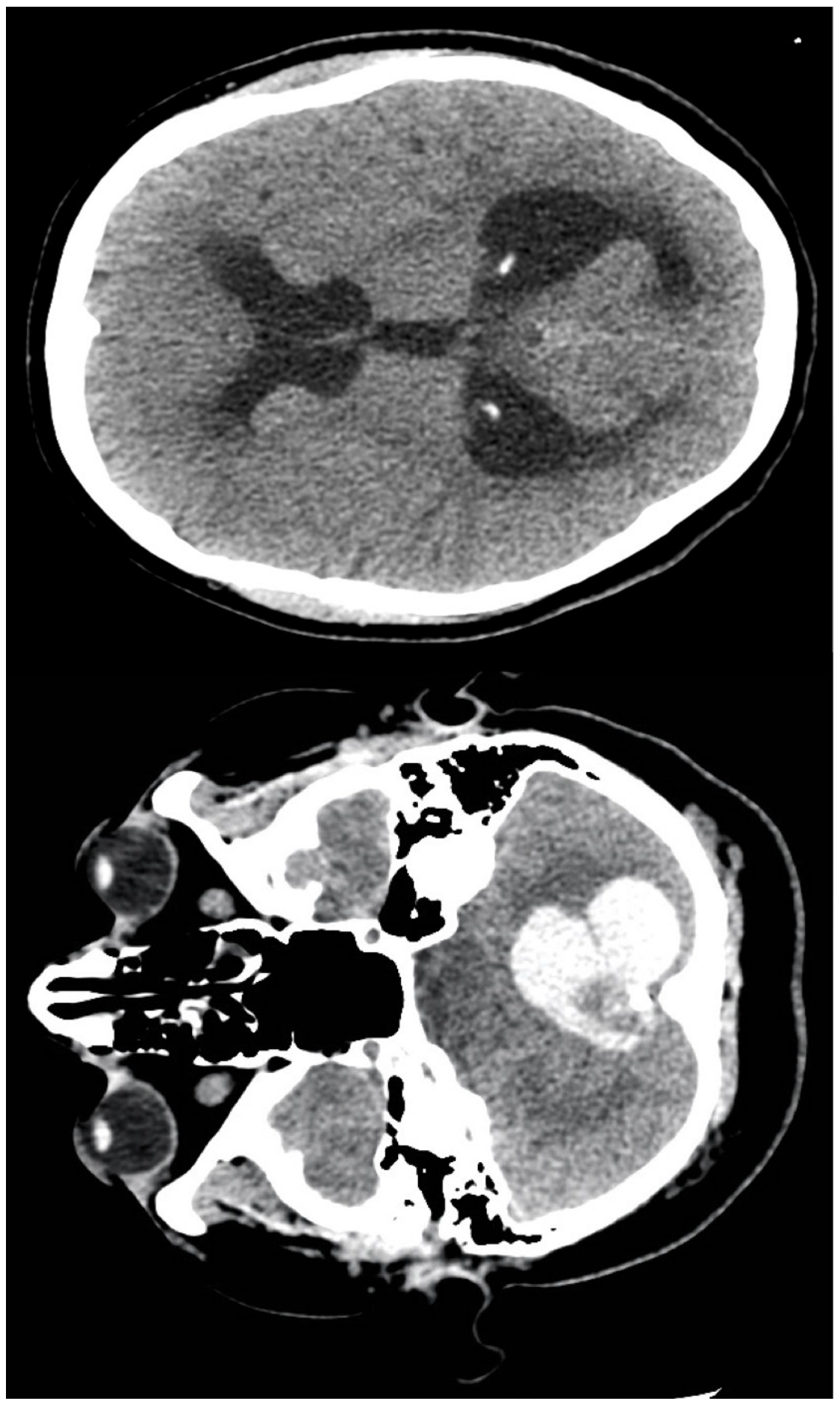

Figure 1: Pre-operative CT imaging (A) Axial CT through posterior fossa showing hyperdense lesion with central calcification; (B) Axial CT through lateral ventricles showing acute hydrocephalus.

oedema in the adjacent cerebellum. A small area of the lesion showed gadolinium enhancement and a focus of susceptibility weighted imaging (SWI) signal dropout. A larger lobulated component showed homogenous signal hyperintensity on T1-weightedimaging with no enhancement and marked hypointensity on T2-weighted imaging with no signal dropout on susceptibility weighted imaging (SWI). The mass herniated through the foramen magnum and there was high T2-weighted signal within the cervical cord, suggestive of early syrinx formation.

The lack of vascular tumour blush or nodule, lack of contrast enhancement, lack of diffusion restriction, and lack of involvement of the IV $\mathrm{V}^{\text {th }}$ ventricle meant more common posterior fossa tumours such as haemangioblastoma, astrocytoma, meningioma, medulloblastoma, epidermoid cyst, or ependymoma were less likely. Due to the homogenous T1-weighted hyperintensity and T2-weighted hypointensity, melanin was suspected and a working diagnosis of a meningeal melanocytoma was suggested. The absence of lipid signal with both T1-weighted and T2-weighted hyperintensity meant dermoid cyst and teratoma were thought less likely. 


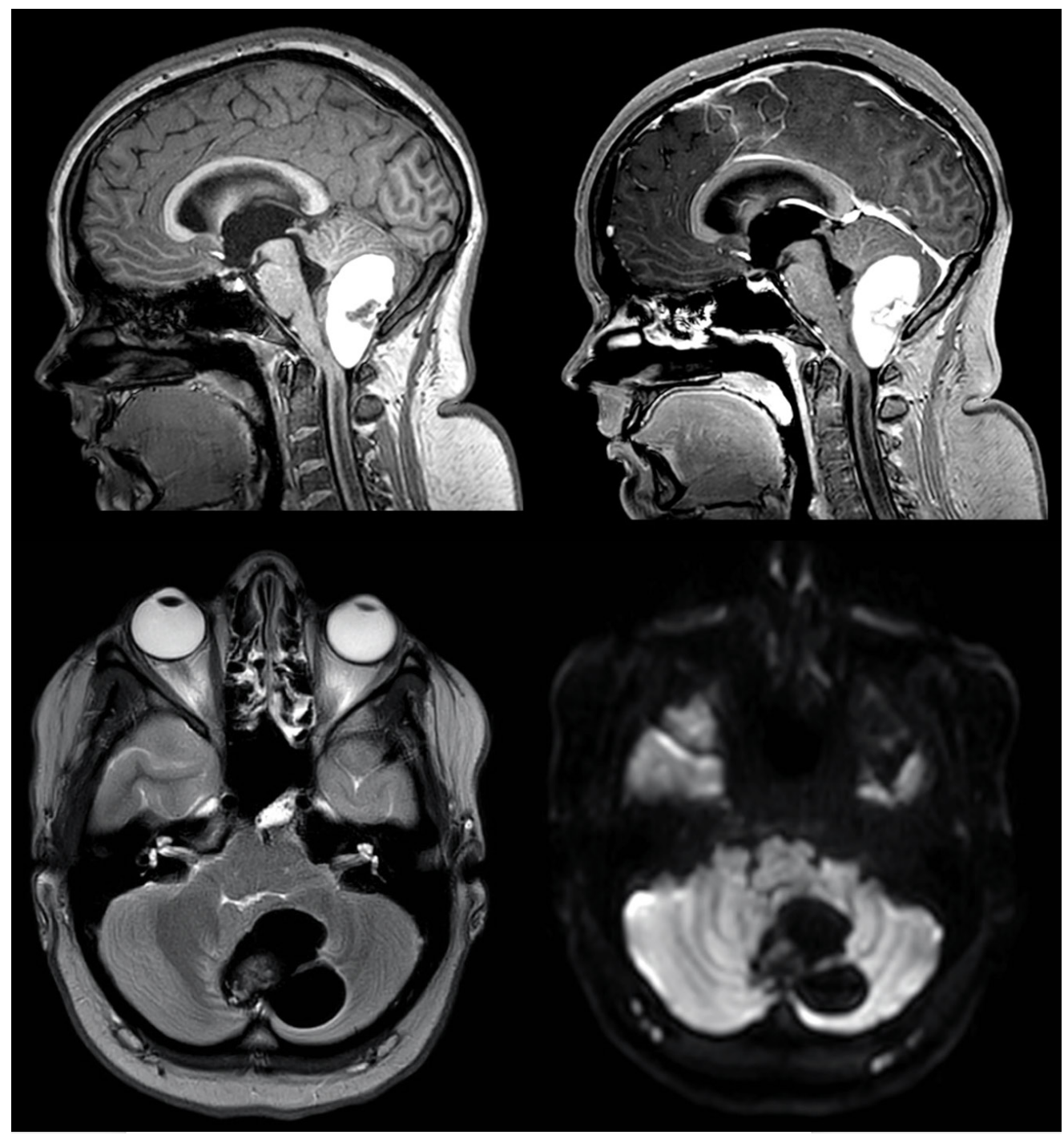

Figure 2: Pre-operative MRI imaging (A) Sagittal T1-weighted image showing posterior fossa hyperintense lesion with smaller hypo-intense central part; (B) Sagittal post-contrast T1-weighted MRI showing central contrast enhancement; (C) Axial T2-weighted MRI with isointense central part and surrounding hypo-intensity; (D) Axial DWI with no diffusion restriction.

A posterior fossa craniotomy was performed. During a midline hair shave, a small dermal sinus containing hair was noted. Afterdural opening, non-pigmented hair was visible over a lobulated green-brown mass within the cerebellum (Figure 3). The mass consisted of cysts containing viscous green fluid and a calcified tooth-like lesion.

Microscopy revealed a cyst lined with simple cuboidal ciliated epithelium and stratified squamous epithelium. Hair shafts, glandular structures, bone and adipose tissue were identified, along with a foreign body giant cell reaction including cholesterol clefts suggestive of cyst rupture. Histopathological analysis therefore confirmed a mature teratoma.

The mass was dissected free from the cerebellum and completely excised. Post-operative imaging showed complete resection of the lesion (Figure 4) with resolution of hydrocephalus and resolution of the cervical syrinx. She made a full post-operative recovery with resolution of diplopia and headaches. She has not required ongoing CSF diversion and surveillance imaging to date (15 months) shows no recurrence.

\section{Conclusion}

Mature teratomas can produce any adult tissue and therefore can have any combination of imaging characteristics $[1,2,4]$. This heterogeneity of MRI findings can lead to diagnostic uncertainty [3,10,11-14]. Here, we have illustrated a case mimicking intracranial haemorrhage or melanin containing tumour. There are no other published cases of mature teratomas with these imaging characteristics in the posterior fossa.

\section{Declarations}

\section{Funding}

No funding was received for this work.

\section{Conflicts of interest}

No conflicts of interest to disclose. 


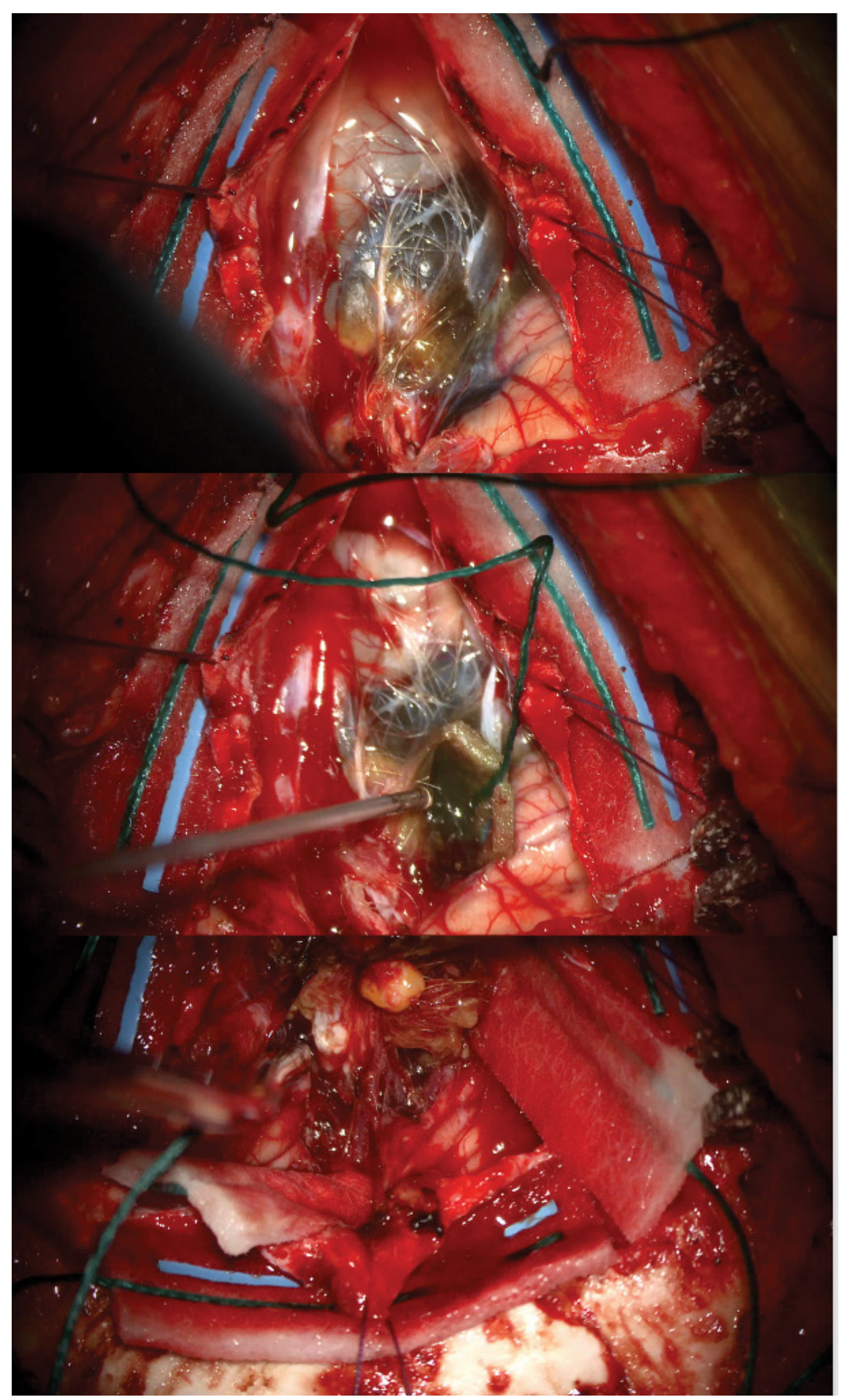

Figure 3: Intra-operative photographs taken in prone position during posterior fossa craniotomy. Orientation: Top of photograph $=$ inferior cerebellum (A) Non-pigmented strands of hair visible over posterior fossa mass following dural opening; (B) Green coloured viscous cyst contents; (C) Calcified tooth-like mass within lesion. 


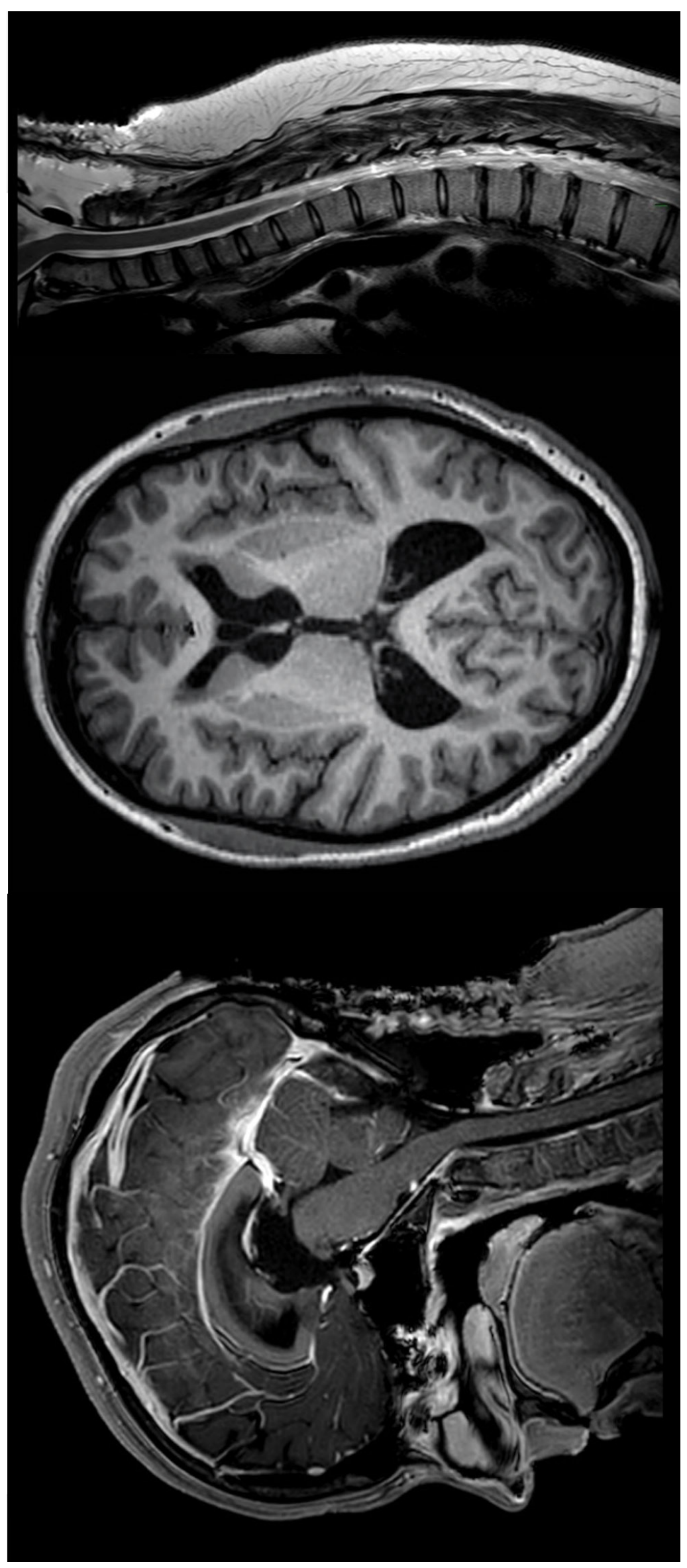

Figure 4: Post-operative imaging (A) Sagittal T1-weighted post-contrast MRI showing complete lesion resection; (B) Axial T1-weighted MRI through the lateral ventricles showing resolution of hydrocephalus; (C) Sagittal T2-weighted cervical spine imaging showing resolution of the cervical cord hyperintensity. 


\section{Availability of data and material}

Available.

\section{Code availability}

Available.

\section{Authors contribution}

All authors contributed to the study conception and design. Material preparation was performed by all authors. The first draft of the manuscript was written by Maia Osborne-Grinter and all authors commented on previous versions of the manuscript. All authors read and approved the final manuscript.

\section{References}

1. Smirniotopoulos JG, Chiechi MV (1995) Teratomas, dermoids, and epidermoids of the head and neck. Radiographics 15: 1437-1455.

2. Agrawal M, Uppin MS, Patibandla MR, Bhattacharjee S, Panigrahi MK, et al. (2010) Teratomas in central nervous system: A clinico-morphological study with review of literature. Neurology India 58: 841-846.

3. Sweiss RB, Shweikeh F, Sweiss FB, Zyck S, Dalvin L, et al. (2013) Suprasellar mature cystic teratoma: An unusual location for an uncommon tumor. Case Reports in Neurological Medicine.

4. Sano K (1999) Pathogenesis of intracranial germ cell tumours reconsidered. J Neurosurg 90: 258-264.

5. Beschorner R, Schittenhelm J, Bueltmann E, Ritz R, Meyermann R, et al. (2009) Mature cerebellar teratoma in adulthood. Neuropathology 29: 176-180.
6. Zavanone $M$, Alimehmeti $R$, Campanella R, Ram-Pini $P$, Locatelli M, et al. (2002) Cerebellar mature teratoma in adulthood. J Neurosurg Sci 46: 35-38.

7. Park KB, Park HS, Lee JI, Suh YL (2007) Mature teratoma in the cerebellar hemisphere of an Adult. J Korean Neurosurg Soc 41: 180-181.

8. Brandes AA, Pasetto LM, Monfardini S (2000) The treatment of cranial germ cell tumours. Cancer Treat Rev 26: 233-242.

9. Matsutani M, Sano K, Takakura K, Fujimaki T, Nakamura O, et al. (1997) Primary intracranial germ cell tumors: A clinical analysis of 153 histologically verified cases. J Neurosurg 86: $446-455$.

10. Liu Z, Lv X, Wang W, An J, Duan F, et al. (2014) Imaging characteristics of primary intracranial teratoma. Acta Radiol 55: 874-881.

11. Daugherty C, Ngo T, Drehner D, Maugans T (2016) Mature teratoma confined to the posterior fossa. Pediatr Neurosurg 51: 93-98.

12. Buetow PC, Smirniotopoulos JG, Done S (1990) Congential brain tumors: A review of 45 cases. AJNR 11: 793-799.

13. Tzubery S, Hadelsberg UP, Ben-David E, Winestone JS, Cohen JE, et al. (2021) Mature cystic teratoma of the posterior fossa - A case report to enrich our data on the subject. Interdisciplinary Neurosurgery 25: 101226.

14. Coulibaly O, El Kacemi I, Fatemi N, Gana R, Saidi A, et al. (2012) Mature posterior fossa teratoma mimicking infratentorial meningioma. Neurochirurgie 58: 40-43. 